\title{
Climatic signals in growth and its relation to ENSO events of two Prosopis species following a latitudinal gradient in South America
}

\author{
BERNAT C. LÓPEZ*, RODOLFO RODRÍGUEZ†, CARLOS A. GRACIA †§ and SANTIAGO \\ SAB ATÉ $₫ \S$ \\ *CREAF (Center for Ecological Research and Forestry Applications) and Unit of Ecology, Department of Animal and Plant Biology \\ and Ecology, Autonomous University of Barcelona, E-08193, Bellaterra, Catalonia, Spain, †Universidad de Piura, Av. Ramón \\ Múgica 131. Urb. San Eduardo. Piura. Perú, ŁCREAF (Center for Ecological Research and Forestry Applications), Autonomous \\ University of Barcelona, E-08193, Bellaterra, Catalonia, Spain, §Faculty of Biology, Department of Ecology, University of Barcelona, \\ Diagonal 645, E-08028 Barcelona, Catalunya, Spain
}

\begin{abstract}
Semiarid environments throughout the world have lost a major part of their woody vegetation and biodiversity due to the effects of wood cutting, cattle grazing and subsistence agriculture. The resulting state is typically used for cattle production, but the productivity of these systems is often very low, and erosion of the unprotected soil is a common problem. Such dry-land degradation is of great international concern, not only because the resulting state is hardly productive but also because it paves the way to desertification. The natural distribution of the genus Prosopis includes arid and semiarid zones of the Americas, Africa and Asia, but the majority of the Prosopis species are, however, native to the Americas. In order to assess a likely gradient in the response of tree species to precipitation, temperature and their connection to El Niño southern oscillation (ENSO) events, two Prosopis species were chosen along a latitudinal gradient in Latin America, from northern Peru to central Chile: Prosopis pallida from a semi-arid land in northern and southern Peru and P. chilensis from a semiarid land in central Chile. Growth rings of each species were crossdated at each sampling site using classical dendrochronological techniques. Chronologies were related with instrumental climatic records in each site, as well as with SOI and N34 series. Cross-correlation, spectral and wavelet analysis techniques were used to assess the relation of growth with precipitation and temperature. Despite the long distance among sites, the two Prosopis species presented similar responses. Thus, the two species' growth is positively correlated to precipitation, while with temperature it is not. In northern Peru, precipitation and growth of $P$. pallida present a similar cyclic pattern, with a period of around 3 years. On the other hand, P. pallida in southern Peru, and P. chilensis also present this cyclic pattern, but also another one with lower frequency, coinciding with the pattern of precipitation. Both cycles are within the range of the ENSO band.
\end{abstract}

Keywords: Algarrobo, Chile, dendrochronology, El Niño, Perú, Prosopis chilensis, Prosopis pallida, semiarid land species, spectral analysis, wavelet analysis

Received 15 February 2005; revised version received 19 January 2006; accepted 23 November 2005

Introduction

In ancient times, extensive shrub and tree stands covered several semiarid areas, but nowadays the vegetation of these environments is usually a sparse mixture

Correspondence: tel. +34 935811920, fax + 34 935814151, e-mail: bernat@creaf.uab.es of woody and herbaceous species. Semiarid environments throughout the world have lost a major part of their woody vegetation and biodiversity due to the effects of wood cutting, cattle grazing and subsistence agriculture. The resulting state is typically used for cattle production, but the productivity of this system is often very low, and erosion of the unprotected soil is a common problem. Such dry-land degradation is of 
great international concern, not only because the resulting state is hardly productive but also because it drives to desertification, which is globally one of the main ecological threats. It has been estimated that $48 \%$ of the dry lands (which represent $31 \%$ of South America's surface) is already degraded, and the regeneration of key tree native species has been proved to be a major problem.

Extreme weather or climate anomalies are often devastating to people, infrastructures and environment in some areas of South America, because of the poor infrastructure and the low socioeconomic development of many of these areas. The usually dry conditions of some semiarid regions of South America and other parts of the world are periodically interrupted by dramatic increases in rainfall associated with the El Niño southern oscillation (ENSO) phenomenon. The ENSO phenomenon is the strongest natural interannual climate fluctuation affecting societies and economics of many countries by flooding and severe droughts (Ropelewski \& Halpert, 1987; Allan et al., 1996). The last two decades have been marked by unusually strong El Niño events in 1982/1983, 1997/1998 and a prolonged activity during 1990-1995. This recent development raised the question of whether or not humaninduced greenhouse warming affects the behavior of the ENSO (Timmermann et al., 1999; Trenberth, 2001), but the historical meteorological southern oscillation index (SOI) and oceanographic sea surface temperature (SST) data are of insufficient length to describe the longterm variability of the ENSO (Stahle et al., 1998; Mann et al., 2000). Therefore, several recent studies have focused on the reconstruction of the paleoclimatic ENSO based on long-term instrumental data, tree-ring proxies, isotopic indicators in coral reefs and ice cores (Schöngart et al., 2004). Despite the ample evidence for annual tree rings in many tropical regions (Worbes, 2002), most dendroclimatic records have been developed in extra-tropical regions, which are too far from the ENSO signal, originated in the tropical Pacific Ocean and are influenced by additional atmospheric circulation patterns (Stahle et al., 1998; Enquist \& Leffler, 2001).

The natural distribution of the genus Prosopis includes arid and semiarid zones of the Americas, Africa and Asia. The majority of the Prosopis species are, however, native to the Americas. The areas that have undergone most deforestation in the Americas are those that once supported the largest Prosopis forests, located in three main regions: Mexico, Peru/Chile and Argentina. This has been due primarily to land clearance for agriculture or ranching, and logging for a variety of wood use (e.g. NAS, 1980). Also, where forests were not completely destroyed, many have undergone continu- ous selective felling and generic depletion, with the best trees preferentially removed over time (Pasiecznik et al., 2001). Lowering of water tables due to water extraction by humans has been blamed for the death of many mature trees in higher rainfall zones of central Africa (Bernard, 1996).

The objective of this study is to establish the relation of two Prosopis species' growth (Prosopis pallida HBK and P. chilensis Molina Stuntz) that habitat the western coast of South America, with climatic conditions (temperature and especially precipitation associated with ENSO events). Our working hypothesis was that although these two species habitat along a latitudinal and climatic gradient, rainfall inputs being much stronger in the north than in the south, they would respond similarly to climate, probably shifting to a more hydric dependence in the north to a more temperature dependence in the south.

\section{Materials and methods}

Prosopis species are all trees or shrubs of varying size (rarely subshrubs), predominantly xerophilous, aculeate, spiny or rarely unarmed (Burkart, 1976). Prosopis species vary widely in their productivity and their relative use and utilization by humans. The list of products profited from Prosopis spp. is long, including wood, pods, leaves, honey and wax, exudates gums, tannins, dyes and fibers and medicines. Characteristics preferred by humans are the production of large amounts of sweet pods, and rapid growth of erect trees with an ability to survive and thrive in poor soils and under drought conditions (Pasiecznik et al., 2001). All Prosopis spp. are nitrogen fixing.

The latitudinal gradient, from north to south, chosen for this study started in Piura (northern Peru), and ended in Central Chile (Fig. 1). In January 2002, several sites in both northern and southern Peru were visited and P. pallida samples were taken in each site. Details about the sampling procedure in northern and southern Peru, as well as results for some northern Peru samples, can be found in López et al. (2005).

In January 2003, several sites of the Región IV in Chile were visited, following an inventory of $P$. chilensis made by the University of La Serena. In each site, and if the $P$. chilensis individuals were not in populated areas or zones susceptible to undergo or to have undergone artificial irrigation, one tree core per tree was extracted at the base of the trunk. Owing to the hardness of the wood, tree cores were taken by means of a special borer for hard wood (HD-borer $300 \mathrm{~mm}$ CSIRO, Australia*, Patience \& Nicholson (Aust.) Pty Ltd., Kaipoi, New Zealand) connected to an independent driller (Tanaka TED262R ${ }^{\dagger}$, Tanaka Kogyo Co., Ltd., Narashino-shi, Chi- 


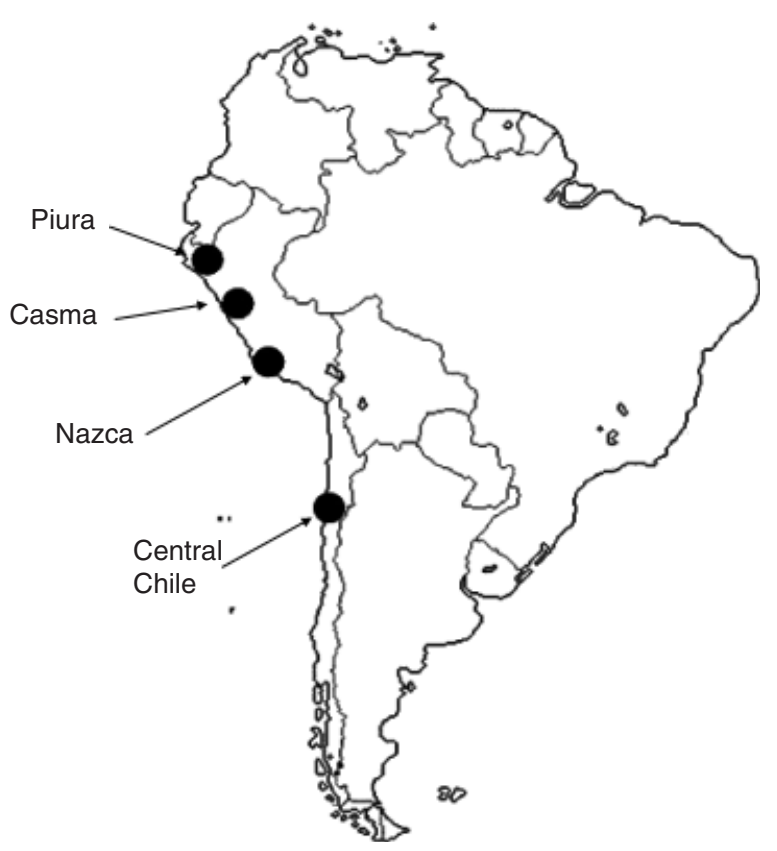

Fig. 1 Locations of the four sampling sites. Prosopis pallida samples were taken from Peruvian sites (Piura, Casma and Nazca), and samples of $P$. chilensis were taken in the IV region (north-central Chile).

ba, Japan). A total of 190 samples in different zones from the IV Region were collected. However, more than half of these trees were discarded either due to the possibility of having been irrigated, or to the bad quality of the samples.

Samples from Peru and Chile were first rough polished with a belt sander, and then with a sheet sander with a sand paper of up to 1000 grit. Samples were observed under a binocular microscope and rings were marked with a very finely sharpened pencil. Samples were then scanned at a very high resolution (1600 dpi) with an Epson Expression 1640 XL scan ${ }^{\circ}$ (Seiko Epson Corp., Nagano, Japan). With this resolution, the scanner yielded a precision of $0.015875 \mathrm{~mm}$. WinDENDRO ${ }^{\mathbb{C}}$ (Regent Instruments, Regent Instruments Inc., Canada) software was used to detect rings, but due to the characteristics of growth rings, the software was unable to detect any ring automatically. However, the agility and the ease of use of WinDENDRO ${ }^{\odot}$ were valuable, so rings were manually marked, using both pencil marks which were already scanned and visual criteria through the screen. Ring-width data were crossdated with COFECHA (Grissino-Mayer, 2001), and many series were discarded due to their bad correlation with the rest. ARSTAN software was used to obtain a master series for each region using the best matching series at each site. To remove long-term growth trends largely attributed to increasing age and tree size, the individual ring- width measurement series were standardized (Fritts, 1976). First, a negative exponential curve was used, and after that, a second detrending using a cubic smoothing spline was performed. The cubic smoothing spline fits a succession of cubic polynomial curves to the data in one pass. The amount of variance to be removed at a particular frequency can be precisely specified, and removes variances of lower frequencies (i.e. longer wavelengths) with a transition to little or no removal of variance of higher frequencies (i.e. shorter wavelengths). In our case, splines were of 30 years for $P$. chilensis, of 15 years for Nazca P. pallida (although the 30-year spline model gave very similar results) and of 10 years for Casma P. pallida (being only slightly stiff applying a 30-year model). The indices for each series were then derived by taking the ratio of the measurement to the fitted value in each year. After that, these indices were prewhitened using an autoregressive model selected on the basis of the minimum Akaike criterion, and combined across all series in each year using biweight robust estimation of the mean to discount the influence of outliers. Program ARSTAN constructed a set of three chronologies: a standard chronology, a residual chronology, containing only the high-frequency variations, and the ARSTAN chronology, composed of the residual chronology with the pooled autoregression reincorporated (Cook, 1985). The output of ARSTAN provided primary dendrochronological statistics, including signal-to-noise ratio (SNR), which can be regarded as an expression of the strength of the observed common signal among trees, the expressed population signal, a measurement of the correlation between the mean chronology derived from the samples and the population (Wigley et al., 1984), and the mean sensitivity (MS), a measure of the relative differences in width between adjacent rings (Fritts, 1976).

Signal-detection techniques decomposed the variance into oscillatory components (frequency domain) or with respect to time lags and spatial distances (time domain). The first approach is the spectral analysis, while the second approach uses the correlation methods (Platt \& Denman, 1975; Chatfield, 1989). Correlation analysis was performed using the program SPSS v11.5 (SPSS Inc., Chicago, Illinois, USA). The master chronologies of our sampling sites (Piura and Chile) were matched against precipitation data. In Peru, meteorological data came from the weather station from the Universidad de Piura, and in Chile, data were from the La Serena Airport and the Vicuña weather station.

Single spectral analyses describe periodically recurring events in time series (Fuller, 1996). The spectra of the tree ring chronologies and climatic series of our sites were analyzed to examine the distribution of the strength of their periodic signal. Spectral analysis as 
well as wavelet analysis were conducted using the chronologies presented in this paper and another one from Piura (northern Peru), obtained by the same authors and presented in López et al. (2005).

In the frequency domain, wavelet analysis (WA) (Mallat, 1989; Daubechies, 1993; Chiu et al., 1994; Lau \& Weng, 1995; Torrence \& Compo, 1998) identifies discontinuities and transitory signals at several scales. The output of WA is a time and frequency variance decomposition obtained by 'filtering' the data with a small, moving, wave-like function (the wavelet base) with changing frequency (Torrence \& Compo, 1998). Among other fields, WA has been applied to investigate vegetation (Bradshaw \& Spies, 1992; Dale \& Mah, 1998;

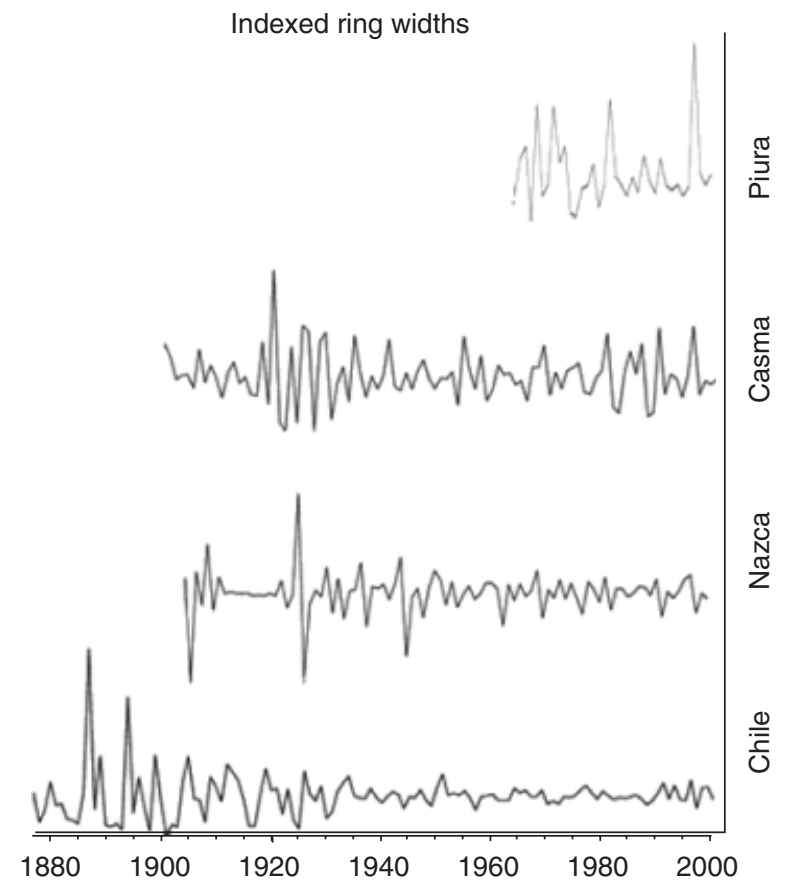

Fig. 2 Indexed ring width chronologies from the four sampling sites (see text for details).
Harper \& MacDonald, 2001), and landscape patterns (Saunders et al., 1998; Brosofske et al., 1999; Li \& Kafatos, 2000). WA was used to analyze all time series (both the vegetation and the climatological ones) in this study, in order to identify possible discontinuity patterns in growth likely related to climate variations.

\section{Results}

\section{Correlations with precipitation and temperature}

From the individual series of growth of $P$. chilensis, we obtained a standardized chronology of 85 years, from 1918 to 2002, for IV the region of Chile. From the P. pallida samples, we also obtained a chronology for the Casma site (from 1908 to 2002) and another one for the Nazca site (from 1977 to 2001) (Fig. 2). The main characteristics of these three chronologies, as well as those of P. pallida from another site (Piura) obtained by the same authors and published in López et al. (2005), are summarized in Table 1. The mean sensitivity generally ranged from 0 (no differences between two adjacent rings) to 2 (zero value next to a nonzero value in the time sequence). Our MS values of the chronologies were all between 0.55 and 0.85 , meaning that width variations were very similar among them, and indicated the presence of a considerable high-frequency variance. More, the low autocorrelation of first-order indicates no trend in our measured series. Trees highly limited by climatically related environmental factors have SNR higher than those of trees from moist and mild climates (Fritts, 1976). Samples from Piura presented much higher SNR than those of the rest, all three of which were very similar. The mean correlation values of our chronologies were also good enough for tropical species, and denoted a relatively good strength of the cross-dating of sing trees within a site.

The correlation between $P$. chilensis chronology and annual precipitation was not significant. However,

Table 1. Main dendrochronological characteristics of the four chronologies as obtained by program ARSTAN

\begin{tabular}{lllll}
\hline & Prosopis pallida (Piura) & P. pallida (Casma) & P. pallida (Nazca) & P. chilensis \\
\hline Period & $1965-2001$ & $1908-2002$ & $1977-2001$ & $1915-2002$ \\
Common period & $1982-2000$ & $1969-2002$ & $1991-2001$ & $1981-2002$ \\
MS & 0.62 & 0.56 & 0.85 & 0.83 \\
EPS & 0.92 & 0.85 & 0.68 & 0.76 \\
SNR & 12.10 & 5.62 & 2.09 & 3.22 \\
MCCP & 0.42 & 0.48 & 0.30 & 0.24 \\
Autocorrelation first order & -0.13 & -0.31 & -0.45 & -0.09 \\
Variance first vector $(\%)$ & 52.23 & 57.82 & 45.54 & 34.51 \\
Number of trees & 95 & 10 & 5 & 14 \\
\hline
\end{tabular}

MS, mean sensitivity; EPS, expressed population signal; SNR, signal-to-noise ratio; MCCP, mean correlation of the common period. 
when the master chronology was correlated with mean monthly precipitation values, a significant and positive correlation appeared between growth and precipitation in March, which is generally the first month of the wet season in Chile (Fig. 3). The Casma (P. pallida) chronology was significantly and positively correlated with annual precipitation (correlation coefficient: 0.569 ). As no precipitation data for the Nazca site were available, the chronology was correlated with precipitation in Piura, giving no significant correlation between them. Correlations with temperature in Peru and Chile were not significant in any of our sampling areas.

\section{Two-sample t-tests}

The likely teleconnection between climate and growth variables and the occurrence of El Niño is shown by two-sample tests (Table 2). Among climatic variables,

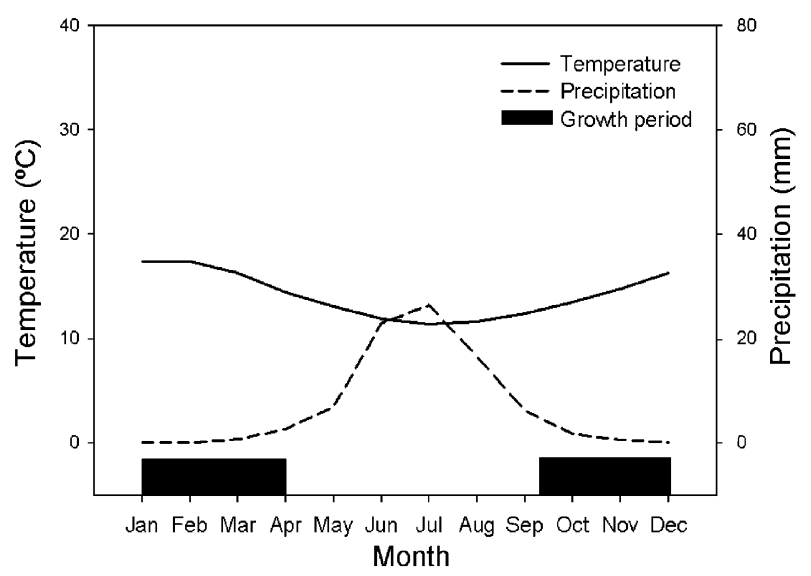

Fig. 3 Monthly precipitation and temperature in the Central Region of Chile. Green rectangles indicate the length of the growth period of Prosopis chilensis.

Table 2. Two-sample test of ring-width indices and climatic factors (temperature and precipitation) between neutral and El Niño years

\begin{tabular}{ll}
\hline & $\begin{array}{l}\text { Confidence level } \\
(P \text { value })\end{array}$ \\
\hline Climatic variables & \\
Temperature Piura/Casma & NS \\
Temperature Central Chile & NS \\
Precipitation Piura/Casma & 0.001 \\
Precipitation Central Chile & 0.013 \\
Vegetation variables & \\
Growth index Prosopis pallida Piura & 0.03 \\
Growth index P. pallida Casma & 0.001 \\
Growth index P. pallida Nazca & NS \\
Growth index P. chilensis & NS \\
\hline
\end{tabular}

NS, not significant. only precipitation showed significant differences between ENSO years and no-ENSO years in the two sites, whereas temperature presented no significant differences between these two groups. On the other hand, growth index values grouped by ENSO and noENSO years presented significant differences only in the northern sites (Piura and Casma), while in the southern sites (Nazca and Chile) they did not.

\section{Spectral and wavelet analysis}

The results of the spectral analysis (SA, see Fig. 4) and the global wavelet spectrum (GW, see Fig. 5 for an example) are summarized in Table 3. Both parameters provided a good estimate of the scales, and even though

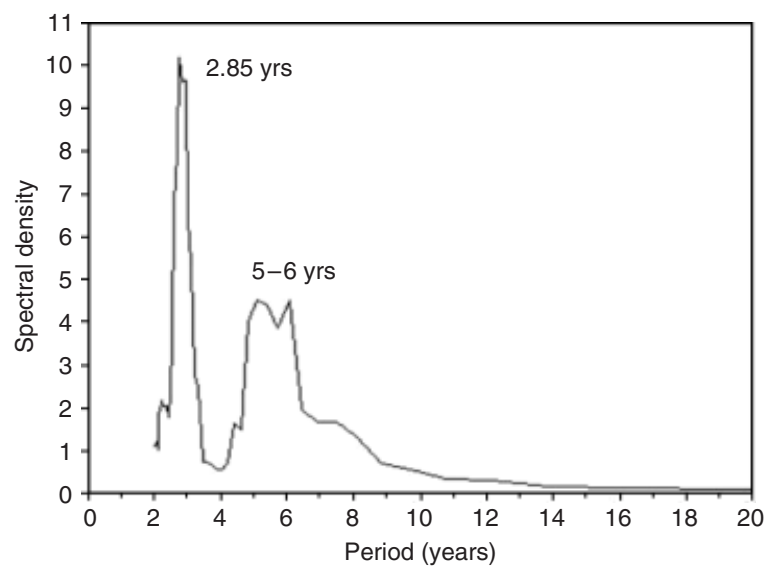

Fig. 4 Single spectral analysis of the indexed ring-width chronology for the Casma chronology of Prosopis pallida.

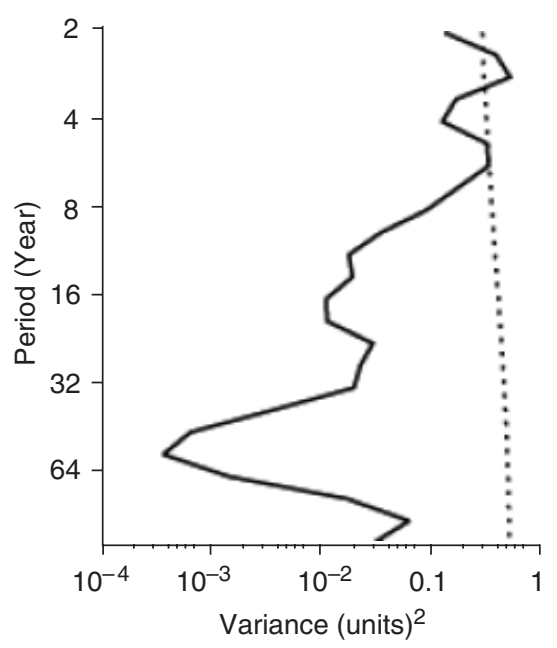

Fig. 5 Example of a global wavelet power spectrum: growth index of Prosopis pallida in Casma. The dashed line indicates the significance for the global wavelet spectrum, assuming the same significance level and background spectrum as in Fig. 6. 
Table 3. Results (period - years, over 10\% of significance level) of the single spectral analysis and the global wavelet spectrum analysis for ring-width indices and climatic variables (precipitation and temperature)

\begin{tabular}{lll}
\hline & $\begin{array}{l}\text { Spectral analysis } \\
\text { (period, years) }\end{array}$ & $\begin{array}{l}\text { Global wavelet spectrum } \\
\text { (period, years) }\end{array}$ \\
\hline Climatic variables & & $\mathrm{NS}\left(2.5^{\dagger}\right)$ \\
$\quad$ Precipitation Piura/Casma & $2-5^{*}$ & $4-8$ \\
Precipitation central Chile & $6.5-8.8$ & 5 \\
Temperature Piura/Casma & $3-5$ & 5 \\
Temperature central Chile & 6.5 & $2.5-3$ \\
Vegetation variables & $2.5-3.5$ & $2.5-3.5 / 5-7$ \\
Growth index Prosopis pallida Piura & $2.5-3 / 5-6$ & $\mathrm{NS}$ \\
Growth index P. pallida Casma & 2 & $3 / 14$ \\
Growth index P. pallida Nazca & $2.5-3 / 14$ & \\
Growth index P. chilensis & & \\
\hline
\end{tabular}

*The spectral analysis presents several peaks and valleys between these two values.

${ }^{\dagger}$ If series was only taken until 1982, i.e. without the two last very strong ENSO events, a significant 2.5-years period appears.

NS, not significant.

they gave no clue about the varying oscillation of the series (Torrence \& Compo, 1998), they gave interesting information regarding the constancy of certain cycles in the series. Precipitation and temperature of Northern Peru (Piura and Casma) presented cycles of around 2-4 years, while the environmental variables of our southernmost studied site (Chile) presented cycles with lower frequencies, approximately every 6 years or more. Both cycles were reflected in the growth patterns of the studied species. Thus, growth series of P. pallida at the two studied communities of Northern Peru (Piura and Casma) presented a growth cycle of around 2-3.5 years (and also 6 years in Casma), while in the case of Nazca, more southerly located, only de SA gave such a periodicity. On the other hand, P. chilensis presents the two cycles in its growth.

The wavelet power spectrum (WP, see Fig. 6 for an example) provides information about the varying oscillation of the series in a time-frequency plot (Torrence \& Compo, 1998). Precipitation in Northern Peru presented very low values in the ENSO band from 1945 until 1975. But after 1975, power values in this band were high or very high. When the series was cut from 1982 on in order to remove the two very strong ENSO events of 1983 and 1998, the ENSO band (6 years) was present during the whole period. Temperature series was too short to perform a reliable wavelet analysis. Regarding growth series of the Piura site, we observed, in the ENSO band, the highest values of power from 1970 until 1985, with a decrease in the signal from 1985 till 1995 and a posterior increase afterwards. The period between 1975 and 1981 was also characteristic for having low power units at 3-year period, but higher at 6year periods. In Casma, the highest values of power were observed, in this series, in the ENSO band at the

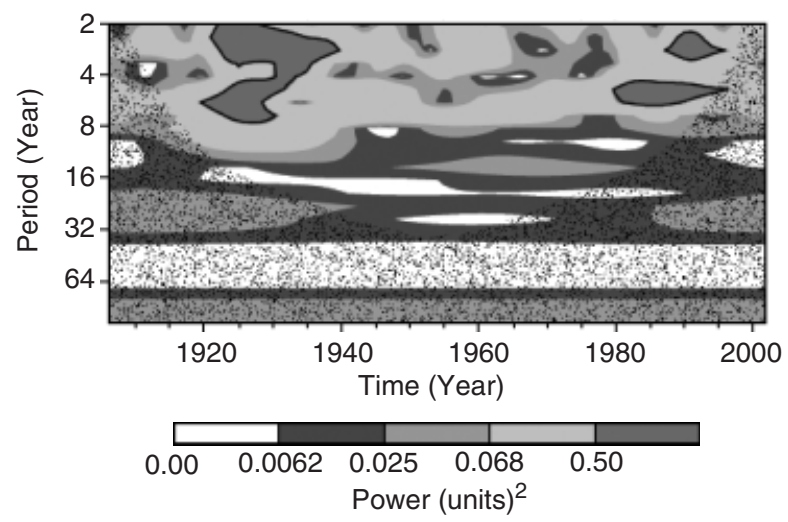

Fig. 6 Example of a wavelet power spectrum: growth index of Prosopis pallida in Casma. The contour levels are chosen so that $75 \%, 50 \%, 25 \%$ and $5 \%$ of the wavelet power are above each level, respectively. The dotted region indicates the cone of influence, where zero padding has reduced the variance. The black contour shows the $10 \%$ significance level, using a red-noise (autoregressive lag 1) background spectrum.

beginning of the 20th century (from 1920 until 1940). From then on and until 1980, we obtained lower signals in the ENSO band. Afterwards, power became higher. Nevertheless, the ENSO band was very clear throughout the whole period. On the other hand, the result of the WP with the Nazca series revealed higher power values between 1982 and 1985 at 2-4-year periods, with a decrease as time increased. From 1985 onward, the band was still visible, but with lower power. For periods of around 6 years, the band was visible for the whole series.

The WP carried out with the Chilean temperature series showed a clear ENSO band for the whole period (1910-1985) at periods of 6-10 years. Relatively high- 
power values for periods of 6-10 years were observed between 1900 and 1925, and between 1945 and 1990. The lowest values of power were observed between 1930 and 1945, also for periods of 4-10 years. Concerning precipitation, the presence of the ENSO band was not very clear. We observed the lowest values of power for the 1965-1975 period. The highest power was observed for periods of 6-10 years between 1970 and 1995. The power values of the growth index series presented a decrease with time in the high-frequency side of the ENSO band (around 2-4 years), the highest values of power occurring in 1925, and decreasing with time, but visible until 1965. The most powerful signals were observed between 1950 and 1985 at a lower frequency (12-14 years). Almost no periodicity signals were visible from 1975 onwards.

\section{Discussion}

Successful cross-dating between individuals of the same site expresses an external oscillating factor influencing tree growth (Worbes, 1995). Cross-dating of the $P$. chilensis and P. pallida (Nazca) ring-widths over the entire life span of the individual trees was not as successful as we had already obtained for P. pallida in Piura (López et al., 2005). Although both species show distinct annual rings, and share similar wood structure characteristics (FAO, López et al., 2005), in the case of $P$. chilensis, this was clearly due to the distribution of the sampled trees, which, to avoid antropic interferences (mainly irrigation), was very sparse, and, thus, microclimatic conditions were likely to prevent a good correlation among samples. Similar reasons could be found for the Nazca site, where it is not that trees are in populated areas, but the remaining population is unfortunately very low. So, $P$. pallida trees are only occasionally found. Thus, the results of these areas should be interpreted more as indications or patterns than those of the Piura site, where the results are more rubust. Our MS value remains in the range of other MS values of species that habitat other arid or semiarid lands of the world (Fritts, 1974; Li et al., 1988; Liang et al., 2001a, b; Morales et al., 2001). The much higher SNR value of the Piura chronology is probably due to the nature of the series. It is much shorter and comprises a period when the two last mega-ENSO events took place (1983 and 1998), which can bias this value with respect to the rest. It can be also viewed in the Casma chronology, closer to Piura than the rest. It is also clear that sites where annual precipitation amounts are higher have higher SNR values, resulting, then, in a lower value in Nazca, where precipitation is very low (P. Rodríguez, personal communication). Mid-way values are found for the Central Chile chronology. The lower mean correlation of the P. chilensis chronology is also significant. Contrary to what was observed in $P$. pallida, which formed clear monospecific stands, $P$. chilensis within a site had a very sparse distribution, always mixed with Acacia macracantha. This could be the cause of this lower correlation among trees.

Although all sampled sites are affected by annual drought periods, none of these two species are deciduous, so cambial activity in the case of these Prosopis species seems not to be controlled by the flushing and the leaf shedding, as described for other tropical trees (Burkart, 1976). However, the existence of annual rings in both Prosopis spp. demonstrates that cambial activity is clearly seasonal. More specialized and physiological studies should, however, be carried out to demonstrate the relation between growth and the hydric status of the tree.

P. pallida showed a good correlation between ring width and precipitation. The lack of correlation between growth of $P$. chilensis and precipitation would suggest that growth of these trees is not as sensitive to rain as $P$. pallida. But this is likely not to be so straightforward. Precipitation patterns in Northern Peru present larger ranges than in Chile and Argentina. So, growth signals are supposed to be more evident. However, it does not mean that $P$. chilensis are not sensitive to precipitation, and, actually, we demonstrate a relationship between these two variables.

Our study suggests that growth of these two Prosopis species in the western coast of South America is likely triggered by the precipitation pulses. Even though growth of trees is also observed in no-ENSO years, more important inputs of water to the ecosystem are not annual in most of these areas, and depend on the occurrence of the ENSO. It has been suggested that ENSO plays, in these areas, an important role in terms of tree establishment (Holmgren et al., 2001; Holmgren, 2001), but we also demonstrate that growth pulses are also correlated, in general, to ENSO events.

Both SOI and N34 indicated the occurrence of ENSO, and having a cyclic pattern, could be the major cause of environmental variability in the latitudinal gradient studied. Thus, both SA and GW showed two cycles for SOI and N34: one with a periodicity of around 3-4 years, and another one with a periodicity of around 6-8 years. The first periodicity range (between quasibiennial and quasiquadriennial) is traditionally considered the El Niño Southern Oscillation (Cole et al., 1993; Stahle et al., 1998). Thus, P. pallida growth pulses, presenting this high-frequency peak, are clearly linked to ENSO events. On the other hand, P. chilensis and southern P. pallida showed lower frequency peaks. This lower frequency has also been reported in some arid areas where ENSO is likely to have an effect. For example, Fichtler et al. (2004) reported periodicities of 6.4-6.9 
years for two tropical tree species from semiarid forests of Namibia, although in one of their chronologies, they also found a peak at a frequency of 0.277 , which corresponds to 3.6 years. They suggest that the explanation for this peak could be climatological, physiological or external. In our case, these low-frequency peaks (although for P. chilensis, we also obtained a 2.5-year cycle) were likely caused by climatological factors, mainly precipitation. However, temperature should also play an important role, especially in Central Chile, where the altitudinal gradient is high and so temperature is likely to vary substantially among sites. Unfortunately, our temperature data were not complete enough to assess it.

Some authors (Rasmusson \& Carpenter, 1982; Schöngart et al., 2004) proposed a broad spectral peak of $2-8$ years to be attributed to ENSO. Urban et al. (2000) found periodicities of up to $10-15$ years cross-correlating $\delta \mathrm{O}^{18}$ isotopes with the SST (Niño 3.4). Thus, the low-frequency peaks that we have obtained for our two southernmost species could be linked to the occurrence of ENSO events. Nevertheless, even not presenting the same frequency as SOI or N34, this periodicity can also be the expression of ENSO in certain areas, as not every El Niño year is wet in the whole west coast of South America. For example, in 1986 and 1976, both ENSO years, precipitation in Central Chile was lower than the average (http://www.meteochile.cl/). As suggested by Fichtler et al. (2004) with other species from African semiarid lands, this peak could also be a harmonic of the first.

As ENSO periodicity is not evenly distributed over time (Wang \& Wang, 1996), and presents different periods at different times, it is not surprising to find different growth peaks or pulses as a response to climate. A wavelet analysis conducted with the SOI series (figure not shown) showed that, the ENSO band (broad range: 2-8 years) was present throughout the whole period studied (1875-2000), but presented clear ups and downs. Thus, for example, between 1920 and 1930 , power values were very low at periodicities of 2-7 years. The ENSO band was lost or slightly visible between 1950 and 1960. On the other hand, the highest power values in the ENSO bands were observed between 1890 and 1915, between 1935 and 1950 and between 1970 and 1990. The N34 index also presents a clear ENSO band (not shown), but again with significant oscillations. Thus, between 1900 and 1915, power values were very low at periods of around 4 years, as well as between 1960 and 1970. The highest values were observed between 1915 and 1960, and from 1975 onwards. Precipitation oscillation in Piura coincided with SOI and N34, having the highest values from 1975 on. Trees' growth in Piura and Casma reflect this oscillation as well. Nazca series also presented some coincidences, but only at low frequencies. In the case of Chile, temperature showed the ENSO band (at 6-10 years) for the whole period, coinciding with SOI, also presenting low power values between 1930 and 1945. Precipitation, on the other hand, had higher power values at the beginning of the century. Growth of $P$. chilensis followed this decreasing pattern with time.

Recent climatic change may bring about rapid environmental changes that may have extreme impacts on tree growth (Jalivaland et al., 2001), and so an impact on the rural communities that depend on these tree species. There is a huge debate about the possible effects of global warming on ENSO strength and/or frequency. Successful long-term climate prediction rests on the issue of whether the unusual severity of these events was a consequence of rising global temperatures (Trenberth \& Hoar, 1996) or was simply representative of natural variability (Harrison \& Larkin, 1997). For example, Timmermann et al. (1999) suggested more frequent El Niño-like conditions and stronger cold events in the tropical Pacific Ocean under a realistic future scenario of increasing greenhouse-gas concentrations. However, currently, one of the largest uncertainties concerns the relationship between ENSO characteristics and changes in the background climate state, whether natural or anthropogenic (Cobb et al., 2003). Cobb et al. (2003) stated that the majority of ENSO variability over the last millennium may have arisen from dynamics internal to the ENSO system itself. More recently, Timmermann (2004) proposed an amplification of the annual cycle in the tropic Pacific due to greenhouse warming, this cycle being attributed to ENSO irregularities.

Precipitation increases in the north of Peru due to ENSO events have been dramatic in the last few ENSO years (1982-1983, 1997-1998 for example). In the south of the country, these increases are not so evident, and in a half-way situation, the north-central area of Chile, the El Niño phenomenon, although not until disaster-causing values, also increased precipitation notably. If an increase in the ENSO activity occured due to greenhouse warming, the two species used in this study would respond differently. We can hypothesize that the growth of $P$. pallida would undergo important increases; growth of $P$. chilensis could also increase its growth if these rains occurred at the beginning of the season. If this increase was only in the way of increasing the frequency of ENSO events, all species would likely experience higher growth throughout their life span.

Extending our results to all semiarid areas with precipitation increases due to global warming, some of these areas could play a more important role in the carbon sequestration balances of terrestrial ecosystems. Despite nowadays arid areas of Latin America playing a 
very poor role in the carbon sequestration balance, and initial changes associated with climate change are unlikely to create conditions significantly beyond the present range of variation (Watson et al., 2000), these changes could have a crucial effect on the rural communities that live in and depend on these forest systems. There are a number of reviews about the early uses of Prosopis sp. in the American continent (Pasiecznik et al., 2001). Records of human use come from archeological evidence, chronicles of early European soldiers, explorers and priests and histories from native populations. Dendroarcheological studies with P. pallida could provide long chronologies of tree growth in areas where these trees were used by native populations. P. pallida logs have been detected in archeological sites in Peru and will soon be used to conduct dendroarcheological research (R. Rodriguez, personal communication). These chronologies may provide valuable information for reconstructing climate events, disturbance, stand development and successional history in arid and semiarid ecosystems of South America.

We demonstrate the connection between ENSO and growth patterns of two important Prosopis species along a latitudinal gradient of South America, covering an important extension of the semiarid landscapes of these sites. The great potential of dendroclimatological studies to obtain more accurate time series in tropical regions is shown, and also evidence of an annual growth rhythm triggered by precipitation patterns in most tropical regions and many tree species (Détienne, 1989; Worbes, 2002). It is essential to find local species spread out enough to perform robust dendroclimatological work, as we have successfully reported for P. pallida. P. chilensis, on the other hand, although being potentially useful to perform this kind of study, presents the handicap of its scarse distribution in nonpopulated areas. Future research should focus more on these regions, where the effects of ENSO on vegetation are important, and where vegetation development has a real connection with the development of the rural communities that live in these areas.

\section{Acknowledgements}

The authors gratefully acknowledge Luis Albán, Dr Squeo and Dr Gutiérrez for their help in the field and their information about P. pallida and P. chilensis. The suggestions of the anonymous reviewers helped considerably improving the quality of the manuscript. We also wish to thank Laura Ganzer for her valuable help in preparing the samples in the CREAF laboratory. We also thank Miquel Angel Rodríguez for his introduction to the wavelet analysis world. This study was supported by the EUINCO project 'Regeneration of Semiarid Plant Communities: The Role of El Niño Southern Oscillation and Herbivory Control' (ICA4-CT-2001-10051).

\section{References}

Allan RJ, Lindesay J, Parker DE (1996) El Niño Southern Oscillation and Climatic Variability. CSIRO Publishing, Melbourne.

Bernard C Étude d'un parc a Prosopis africana au Nord Cameroun (Cas du village de Holom, en pays Musey). IRAD-Project Garoua II/CIRAD-Forêt/ORSTOM/ICRAF. (1996). Montpellier, France, CIRAD-Forêt.

Bradshaw GD, Spies TA (1992) Characterizing canopy gap structure in forests using wavelet analysis. Journal of Ecology, 80, 205-215.

Brosofske KD, Chen J, Crow TR et al. (1999) Vegetation responses to landscape structure at multiple scales across a northern Wisconsin, USA, pine barrens landscape. Plant Ecology, 143, 203-218.

Burkart A (1976) A monograph of the genus Prosopis (Leguminosae subfam. Mimosoidae) (Part 1 and 2). Catalogue of the recognized species of Prosopis. Journal of the Arnold Arboretum, 57, 219-249.

Chatfield C (1989) The Analysis of Time Series: An Introduction. Chapman \& Hall, London.

Chiu CK, Montefusco L, Puccio L (1994) Wavelets: Theory, Algorithms and Applications. Academic Press, San Diego.

Cobb KM, Charles CD, Cheng H et al. (2003) El Niño/southern oscillation and tropical Pacific climate during the last millennium. Nature, 424, 271-276.

Cole JE, Fairbanks RG, Shen GT (1993) Recent variability in the southern oscillation. Isotopic results from a tarama atoll coral. Science, 260, 1790-1793.

Cook ER (1985) A time series analysis approach to tree-ring standardization. Thesis/Dissertation, University of Arizona, Tucson.

Dale MRT, Mah M (1998) The use of wavelets for spatial pattern analysis in ecology. Journal of Vegetation Science, 9, 805-814.

Daubechies I (1993) Different perspectives on wavelets (eds Daubechies I), pp. 205. American Mathematical Society, Providence, Rhode Island.

Détienne P (1989) Appearance and periodicity of growth rings in some tropical woods. IAWA Bulletin, 10, 123-132.

Enquist BJ, Leffler AJ (2001) Long-term tree ring chronologies from sympatric tropical dry-forest trees: individualistic responses to climatic variation. Forest Ecology and Management, 17, 41-60.

Fichtler E, Trouet V, Beeckman H et al. (2004) Climatic signals in tree rings of Burkea africana and Pterocarpus angolensis from semiarid forests in Namibia. Trees, 18, 422-451.

Fritts HC (1974) Relationships of ring widths in arid site conifers to variations in monthly temperature and precipitation. Ecological Monographs, 44, 411-440.

Fritts HC (1976) Tree Rings and Climate. Teh Blackburn Press, New Jersey.

Fuller WA (1996) Introduction to Statistical Time Series. John Wiley, New York.

Grissino-Mayer HD (2001) Evaluating crossdating accuracy: a manual and tutorial for the computer program COFECHA. Tree-Ring Research, 57, 205-221.

Harper KA, Macdonald SE (2001) Structure and composition of riparian boreal forest: new methods for analysing edge influence. Ecology, 82, 649-659. 
Harrison DE, Larkin NK (1997) The darwin sea level pressure record, 1876-1996: evidence for climate change? Geophysical Research Letters, 24, 1779-1782.

Holmgren M (2001) El Niño as a window of opportunity for the restoration of degraded arid ecosystems. Ecosystems, 4, 151159.

Holmgren M, Scheffer M, Ezcurra E et al. (2001) El Niño effects on the dynamics of terrestrial ecosystems. Trends in Ecology and Evolution, 16, 89-94.

Jalivaland H, Jalali SG, Akbarnia M et al. (2001) Growth response of eight harwood species to current and past climatic variations using regression models. Journal of Agricultural Science and Technology, 3, 209-225.

Lau KM, Weng H (1995) Climate signal detection using wavelet transform: how to make a time series sing. Bulletin of the American Meteorological Society, 76, 2391-2402.

Li Z, Kafatos M (2000) Interannual variability of vegetation in the United States and its relation to El Niño Southern Oscillation. Remote Sensing of Environment, 71, 239-247.

Li B, Yong S, Liu Z (1988) The vegetation of the Xilin river basin and its utilisation. In: Inner Mongolia Grassland Ecosystem Research Station, ed. Research on Grassland Ecosystem 3: 84-183. Science Press, Beijing, (Chinese).

Liang E, Shao X, Hu Y et al. (2001a) Variation in tree ring growth indices of Picea meyeri from the sandy land in the steppe of Inner Mongolia. Acta Phytoecologica Sinica, 25, 190-194.

Liang E, Shao X, Hu Y et al. (2001b) Dendroclimatic evaluation of climate-growth relationships of Meyer spruce (Picea meyeri) on a sandy substrate in semi-arid grassland, north China. Trees, $15,230-235$

López BC, Sabaté S, Gracia CA et al. (2005) Wood anatomy of Prosopis pallida H.B.K. from Peru and its suitability for dendrochronology. Journal of Arid Environments, 61, 541-554.

Mallat SG (1989) A theory for multiresolution signal decomposition: the wavelet representation. IEEE (Institute of Electrical and Electronic Engineers) Transactions on Pattern Analysis of Machine Intelligence, 11, 674-693.

Mann ME, Bradley RS, Hughes MK (2000) Long-term variability in the El Niño Southern Oscillation and associated teleconnections. In: El Niño and the Southern Oscillation: Multiscale Variability and its Impacts on Natural Ecosystems and Society (eds Diaz HF, Markgraf V), pp. 357-412. Cambridge University Press, Cambridge.

Morales MS, Villalba R, Grau HR et al. (2001) Potencialidad de Prosopis ferox Griseb (Leguminosae, subfamilia: Mimosoideae) para estudios dendrocronológicos en desiertos subtropicales de alta montaña. Revista Chilena de Historia Natural, 74, 865-872.

NAS NAoS (1980) Firewood Crops, Schrub and Tree species for Energy Production. National Academic Press, Washington, DC, USA.

Pasiecznik NM, Felker P, Harris PJC et al. (2001) The Prosopis juliflora-Prosopis pallida Complex: A Monograph. HDRA, Coventry, UK.
Platt T, Denman KL (1975) Spectral analysis in ecology. Annual Review of Ecological Systems, 6, 189-210.

Rasmusson EM, Carpenter TH (1982) Variations in tropical sea surface temperature an dsurface wind fields associated with the southern oscillation El Niño. Monthly Weather Review, 110, 354-384.

Ropelewski CF, Halpert MS (1987) Global and Regional Scale Precipitation Patterns Associated with the El Nino/Southern Oscillation. Monthly Weather Review, 115, 1606-1626.

Saunders SC, Chen J, Crow TR et al. (1998) Hierarchical relationships between landscape structure and temperature in a managed forest landscape. Landscape Ecology, 13, 381-395.

Schöngart J, Junk WJ, Piedade MT et al. (2004) Teleconnection between tree growth in the Amazonian floodplains and the El Niño-Southern Oscillation effect. Global Change Biology, 10, 683-692.

Stahle DW, D'Arrigo RD, Krusic PJ et al. (1998) Experimental dendroclimatic reconstruction of the Southern Oscillation. Bulletin of the American Meteorological Society, 79, 21372151.

Timmermann A, Oberhuber J, Bacher A et al. (1999) Increased El Niño frequency in a climate model forced by future greenhouse warming. Nature, 398, 694-697.

Timmermann A (2004) Intensification of the annual cycle in the tropical Pacific due to greenhouse warming. Geophysical Research Letters, 31, L12208.

Torrence C, Compo GP (1998) A practical guide to wavelet analysis. Bulletin of the American Meteorological Society, 79, 6178.

Trenberth KE (2001) Climate variability and global warming. Science, 293, 48 .

Trenberth K, Hoar T (1996) The 1990-1995 El Niño Southern Oscillation event: Longest on record. Geophysical Research Letters, 57, 60

Urban FE, Cole JE, Overpeck JT (2000) Influence of mean climate change on climate variability from a 155-year tropical Pacific coral record. Nature, 407, 989-993.

Wang B, Wang Y (1996) Temporal structure of the southern oscillation as revealed by waveform and wavelet analysis. Journal of Climate, 9, 1586-1598.

Watson AJ, Bakker DCE, Ridgwell AJ et al. (2000) Effect of iron supply on southern ocean $\mathrm{CO}_{2}$ uptake and implications for glacial atmospheric $\mathrm{CO}_{2}$. Nature, 407, 730-733.

Wigley TML, Briffa KR, Jones PD (1984) On the average values of correlated time series, with application in dendroclimatology and hydrometeorology. Journal of Climate Application and Meteorology, 23, 201-213.

Worbes M (1995) How to measure growth dynamics in tropical trees - a review. IAWA Bulletin, 16, 337-351.

Worbes M (2002) One hundred years of tree-ring research in the tropics - a brief history and an outlook to future challenges. Dendrochronologia, 20, 217-231. 